\title{
Accuracy And Cost Of U.S. Financial Data
}

Frank Flanegin, Robert Morris University, USA

Stanko Racic, Robert Morris University, USA

Denis Rudd, Robert Morris University, USA

\begin{abstract}
Data from The Center for Research in Security Prices (CRSP) has been widely recognized and accepted as the premier source of research quality U.S. stock market data for more than 40 years. As a result of advances in information technology, other sources of U.S. stock market data became available during the last decade. The purpose of this study is to analyze the accuracy of data from Yahoo, MSN Money and Worden Brothers TeleChart, against CRSP, by comparing their closing prices for 30 companies included in the Dow Jones Industrial Index and 30 randomly selected companies from the smallest quintal of S\&P 500 firms, over the five year period from 01/01/2003 through 12/31/2007. Preliminary findings are based on the limited time period and size of the sample. While CRSP is undoubtedly "the place" to gather quality financial information, nonCRSP sources of financial data, perhaps not as robust as CRSP, are sufficiently accurate to support research and teaching in quality learning environments. Furthermore free sources of financial data e.g. MSN Money, resemble CRSP as well as, if not better than, commercial TeleChart. Results suggest that Yahoo and particularly MSN Money are acceptable transitory substitutes for CRSP for research purposes, especially for securities from larger, well known firms, and more than adequate for teaching needs. Manual data downloading for MSN Money and Yahoo can be automated with Excel add-in or free shareware software.
\end{abstract}

\section{INTRODUCTION}

Q ntil the early 1990s, two necessary conditions for conducting research in finance were having access to a main frame computer and data, neither of which was cheap. In its basic form data often included historical stock market data from University of Chicago's Center for Research in Security Prices (CRSP) and accounting statements data from Standard and Poor's COMPUSTAT.

CRSP was founded in 1960. Today the basic data set includes daily, weekly and monthly volume and stock prices, dividends, shares outstanding, capital changes and delisting information for companies listed on New York Stock Exchange (since 1926), American Exchange (since 1962) and NASDAQ (since 1972). COMPUSTAT service started in 1962. Today it covers 75,000 global corporate and government securities, providing decades of quarterly and annual accounting data, depending on when the company was added to the database.

Main frame computers in the early 1990s required large, sound proof rooms, a lot of electricity and their own cooling systems. Since storage capacity was very expensive, universities often assigned modest memory allocations to individual users. Most current and frequently used research data was kept on hard drives, but less sought after data and data compiled for specific research projects were stored on computer tapes which required the system operator to physically find and mount the specific tape. Data sets with racks upon racks of computer tapes and main frame computers together with their expensive ongoing stuffing and maintenance, required substantial physical and financial resources that not all universities were able and/or willing to spare.

Technological improvements eliminated the need for costly main frame computers. They were successfully replaced by cheaper, much smaller and maintenance friendly PCs and work stations, with equivalent or superior computing power and storage capacity, requiring one time cost of purchasing. However, continuous, long-term subscription to accurate comprehensive data, provided through CRSP and COMPUSTAT, remains the necessary, but still very expensive and unfortunately not sufficient, condition for quality research in finance. Transformation from a teaching to a research institution does not occur over night. Justifying a purchase of CRSP and 
COMPUSTAT creates pressure for both administrators and faculty. Fortunately there are potential on-line substitutes, which are somewhat inferior to but much less expensive than COMPUSTAT and especially CRSP.

Improvements in computing and information technology combined with unprecedented prosperity during the 1990s greatly increased the number of people who invested in the stock market. Many on-line outfits started providing financial data, with research or analysis tools, free of charge or at very affordable prices on the World Wide Web. The business model for free providers is based on advertisement revenues from site visitors or support from financial intermediaries trying to increase the number of fee paying traders. Non-free providers justify their price by offering additional or enhanced services geared toward active investors and day traders.

Standard features on free sites include utilities for stock symbol lookup, updating price quotes with 15 minutes delay, historical charts, key statistics and financials, company and industry related news and information, analysts' coverage and analytical tools. Many sites provide stock screeners and other utilities for finding stocks with desired characteristics. Free membership gives access to additional benefits, like access to real time quotes, etc.

Individual investors are not the only ones benefiting from free stock market data. Combined with Microsoft Excel, free stock market data allows finance theory to be applied to real world problems and issues, greatly improving students understanding of and motivation for finance (Maher, Schooley and Fry (2001) and Sachdeva (2007)). Optimal diversification is no longer limited to paper and pencil calculations to determine portfolios of risky assets, or their combinations, with risk free assets. Estimating Index and Capital Asset Pricing Models no longer means teaching abstract theory which frustrates or puts to sleep many students.

Based on a limited sample scope and time period, this paper provides preliminary evidence on the accuracy of U.S. stock market data from several sources and gauges their suitability as potential CRSP substitutes. Previous comparisons, from the late 1990s (Lankford and O'Neill (1999) and McCracken, Spector and Lake (1998)), were less rigorous, mostly based on anecdotal evidence and aimed toward private investors since they did not include CRSP. Analysis is focused on Yahoo, MSN Money and Warden Brothers TeleChart. The first two are better known sources of free-data. TeleChart was chosen for convenience reasons. Closing prices for five years (January 1, 2003 through December 31, 2007) were collected for two samples of securities. The first one includes 30 securities in the Dow Jones Industrial Index. To check the coverage of companies that are less known than Blue Chip firms, the second sample contains 30 randomly chosen securities (listed in the Appendix at the end of the paper) from the smallest quintile of S\&P 500 Index. Accuracy of data is measured based on absolute value of levels and rates of differences between prices and returns from alternative sources of data and CRSP. Description of data from different sources and their specific ways of dealing with dividend and stock split adjustments, as well as their treatment of missing data, is presented in the next section. Concluding remarks follow analysis of data accuracy.

\section{DATA}

Each of the four sources of stock market data reviewed treats dividend and stock split adjustment, as well as days when stock did not trade, in a specific way. Adjustments for these differences have to be made in order to make alternative data compatible with CRSP.

CRSP provide historical open, high, low and closing prices. CRSP is the only source of data where volumes are the sum of even and uneven lots and represent actual historical number of trades. The other three sources report adjusted volumes rounded to even lots. Using cumulative adjustment factors CRSP historical prices and volumes can be converted into dividend and stock split adjusted values. For days when there was no trading activity open prices on CRSP are not reported, closing prices are negative and volumes are recorded as zero. In addition to historical open, high, low and closing prices, data at Yahoo also contains adjusted closing prices. All prices on MSN Money and TeleChart are only presented as adjusted. MSN Money reports no price or volume data on dates when a specific stock was not traded. Instead of number of trades TeleChart volumes report number of even lots traded and have to be multiplied by 100 to make them comparable with other data sources. For days with no trading activity, indicated by zero volume, open, high, low and closing price are equal to the last closing price in both TeleChart and Yahoo data bases. 
Characteristics of closing prices for 30 securities from Dow Jones Industrial Index and 30 randomly selected companies from the smallest quintile of S\&P500 Index, collected from different data sources, are depicted in Tables 1 and 2.

Null hypothesis that mean closing prices from two samples with different number of observations are the same was tested using t-test statistic:

$$
t_{\text {data source }=\text { CRSP }}=\frac{\overline{P_{\text {data source }}}-\overline{P_{C R S P}}}{\sqrt{\text { Var data source } / N_{\text {data source }}+V a r_{\text {CRSP }} / N_{\text {CRSP }}}},
$$

where $\quad \bar{P}_{i} \quad$ is average closing price from data source $\mathrm{i}$,

$\operatorname{Var}_{i}$ is variance of closing prices from data source $i$ and

$\mathrm{N}_{\mathrm{i}}$ is number of observations from data source $\mathrm{i}$.

Table 1: Closing Prices for 30 Dow Jones Industrial Index Securities (1/1/03 - 12/31/07)

\begin{tabular}{|l|l|l|l|l|l|l|}
\hline \multirow{2}{*}{ Stat } & CRSP & TeleChart & MSN Money & Yahoo \\
\cline { 2 - 7 } & Cls Price & Adj Cls Price & Adj Cls Price & Adj Cls Price & Cls Price & Adj Cls Price \\
\hline Count & 37,740 & 37,740 & 37,740 & 37,740 & 37,740 & 37,740 \\
\hline Min & 12.38 & 12.38 & 12.38 & 12.38 & 12.38 & 10.94 \\
\hline Max & 144.69 & 119.60 & 119.60 & 119.60 & 144.69 & 117.78 \\
\hline Avg & 48.60 & 45.41 & 45.42 & 45.43 & 48.60 & 42.41 \\
\hline ST & 21.16 & 18.15 & 18.16 & 18.16 & 21.16 & 17.95 \\
\hline t-test & & -0.07 & -0.11 & 0.00 & $22.87 * * *$ \\
\hline
\end{tabular}

$*, * *, * * *$ indicate statistical significance at $10 \%, 5 \%$ and $1 \%$ level.

Statistics in Table 1 indicate data sources can be divided into two somewhat different groups. Since unadjusted closing prices from CRSP and Yahoo have exactly the same descriptive statistics and value of t-statistics is zero, null hypothesis that CRSP and Yahoo means are identical cannot be rejected. Adjusted closing prices are not so homogeneous. Adjusted prices from CRSP, TeleChart and MSN Money have the same range of values, and slightly different averages and standard deviations. For these data sources' null hypotheses, that their means are equal to the CRSP mean, also could not be rejected. Adjusted prices from Yahoo are different from other data sources in every aspect other than their count and hence the value of t-statistic is large enough to reject the null hypothesis the mean adjusted price for Yahoo and CRSP are the same. Since Dow Jones Industrial securities actively trade every day, the count was the same for all types of prices from all data sources.

Table 2: Closing Prices for 30 Small S\&P 500 Securities (1/1/03 - 12/31/07)

\begin{tabular}{|c|c|c|c|c|c|c|}
\hline \multirow{2}{*}{ Stat } & \multicolumn{2}{|c|}{ CRSP } & \multirow{2}{*}{$\begin{array}{c}\text { TeleChart } \\
\text { Adj Cls Price }\end{array}$} & \multirow{2}{*}{$\begin{array}{l}\text { MSN Money } \\
\text { Adj Cls Price }\end{array}$} & \multicolumn{2}{|c|}{ Yahoo } \\
\hline & Cls Price & Adj Cls Price & & & Cls Price & Adj Cls Price \\
\hline Count & 31,974 & 31,974 & 34,245 & 32,259 & 32,031 & 32,031 \\
\hline Min & 0.06 & 0.24 & 0.24 & 0.24 & 0.06 & 0.06 \\
\hline Max & 50.71 & 50.71 & 66.80 & 66.80 & 50.71 & 66.80 \\
\hline Avg & 5.95 & 5.74 & 7.76 & 6.20 & 5.94 & 6.20 \\
\hline ST & 6.68 & 5.22 & 7.84 & 5.72 & 6.68 & 5.84 \\
\hline t-test & & & $-39.28 * * *$ & $-10.67 * * *$ & 0.19 & $-10.46 * * *$ \\
\hline
\end{tabular}

$*, * *, * * *$ indicate statistical significance at $10 \%, 5 \%$ and $1 \%$ level. 
Descriptive statistics in Table 2 show that coverage of small S\&P 500 firms is not so concurrent, which is expected given that these firms are not as closely scrutinized as ones from the Dow Jones Industrial Index. For the five year period that was analyzed, all data sources, except MSN Money, reported 35,982 closing prices. However, when days with no trading activity were eliminated, each data set had a different number of closing prices, with Yahoo having the number of observations closest to CRSP. Excluding count and $\$ 0.01$ difference in average price, statistics for unadjusted prices from CRSP and Yahoo are again identical, resulting in a low value of the t-statistic, and the failure to reject the null hypothesis. The situation with adjusted prices is very different. While several data sources have some statistics that are identical, no two sources have all statistics that were the same. CRSP shared only minimum price with some other sources. TeleChart and MSN Money had the same extreme prices but no other statistic was common to both. The only two statistics matching characteristics for MSN Money and Yahoo were average and maximum price. Given such disparity in value of statistics and the large value of $t$-statistic, the null hypothesis was rejected for adjusted prices from all data sources. Results from Table 2 indicate that TeleChart has less resemblance to CRSP than both MSN Money and Yahoo, which have the same mean.

Since the ultimate goal of this analysis is to identify data source with returns that are the closest to CRSP, statistics for absolute value of returns for Dow Jones and small S\&P 500 securities are presented in Tables 3 and 4. Absolute values of returns eliminate canceling out of positive and negative changes in prices, magnifying discrepancies and giving weight to our results.

As was the case with unadjusted prices, statistics for unadjusted returns from CRSP and Yahoo are identical. Contrary to somewhat heterogeneous results for adjusted prices, the only difference between adjusted returns from CRSP and other data sources is a one basis point lower maximum return for adjusted returns from Yahoo. Based on the t-test statistic, the null hypotheses that the mean return from CRSP and alternative data sources with different number of observations are the same, could not be rejected.

Table 3: Returns for 30 Dow Jones Industrial Index Securities (1/1/03 - 12/31/07)

\begin{tabular}{|l|c|c|c|c|c|c|}
\hline \multirow{2}{*}{ Stat } & \multicolumn{2}{|c|}{ CRSP } & TeleChart & MSN Money & \multicolumn{2}{c|}{ Yahoo } \\
\cline { 2 - 7 } & Cls Return & Adj Cls Return & Adj Cls Return & Adj Cls Return & Cls Return & Adj Cls Return \\
\hline Count & 37,710 & 37,710 & 37,710 & 37,710 & 37,710 & 37,710 \\
\hline Min & 0.00 & 0.00 & 0.00 & 0.00 & 0.00 & 0.00 \\
\hline Max & 50.85 & 26.78 & 26.78 & 26.78 & 50.85 & 26.77 \\
\hline Avg & 1.00 & 0.99 & 0.99 & 0.99 & 1.00 & 0.99 \\
\hline ST & 1.19 & 0.99 & 0.99 & 0.99 & 1.19 & 0.99 \\
\hline t-test & \multicolumn{7}{|l}{} & 0.02 & -0.01 & 0.01 & 0.23 \\
\hline
\end{tabular}

Similar to price patterns, unadjusted returns for small S\&P 500 securities are almost the same, with four basis points difference in standard deviations. Substantial differences in statistics for adjusted prices from different data sources in Table 2 all but disappear when returns are used, especially for extreme returns which are the same for all samples. While average adjusted returns from Yahoo and CRSP are the same, average adjusted return for MSN Money is just one basis point above CRSP. Both data sources have almost identical standard deviations with CRSP. Adjusted returns from TeleChart are still the least similar to CRSP, both in terms of average and standard deviations, making it the only data source where the null hypothesis was rejected.

Table 4: Returns for 30 Small S\&P 500 Securities (1/1/03 - 12/31/07)

\begin{tabular}{|l|c|c|c|c|c|c|}
\hline \multirow{2}{*}{ Stat } & \multicolumn{2}{|c|}{ CRSP } & TeleChart & MSN Money & \multicolumn{2}{c|}{ Yahoo } \\
\cline { 2 - 7 } & Cls Return & Adj Cls Return & Adj Cls Return & Adj Cls Return & Cls Return & Adj Cls Return \\
\hline Count & 29,782 & 29,784 & 33,099 & 30,032 & 29,808 & 29,807 \\
\hline Min & 0.00 & 0.00 & 0.00 & 0.00 & 0.00 & 0.00 \\
\hline Max & 212.57 & 212.57 & 212.57 & 212.57 & 212.57 & 212.57 \\
\hline Avg & 2.94 & 2.94 & 2.77 & 2.95 & 2.94 & 2.94 \\
\hline ST & 4.28 & 4.26 & 4.23 & 4.30 & 4.24 & 4.23 \\
\hline t-test & \multicolumn{7}{|r|}{} & $4.82^{* * *}$ & -0.44 & -0.04 & -0.03 \\
\hline
\end{tabular}

$*, * *, * * *$ indicate statistical significance at $10 \%, 5 \%$ and $1 \%$ level. 


\section{ACCURACY ANALYSIS}

Instead of inferring about resemblance of prices and returns between CRSP and alternative data sources based on their sample statistics, levels and rates of paired differences between data sets were also analyzed. Unadjusted and adjusted prices from Yahoo were paired against corresponding CRSP's unadjusted and adjusted prices. Adjusted prices from other data sources were paired against both CRSP's unadjusted and adjusted prices. Given that returns are more important for research than prices and since it is possible that returns from different data sources are better co-integrated with CRSP than their prices, the analysis of paired differences in returns was performed. Due to variations in stock prices average price difference of $\$ 0.01$ between sample means could be misleading. Hence, price and return paired differences were standardized with CRSP values, creating percentage change. Assuming that the price and return differences are normally distributed, and that their variances are not equal, the null hypothesis - the mean of paired differences is zero - is tested using the t-statistic:

$$
t=\frac{\bar{d}}{S T_{d} / \sqrt{N_{d}}},
$$

where $\bar{d}$ is average paired difference,

$\mathrm{ST}_{\mathrm{d}}$ is standard deviation of paired differences and

$\mathrm{N}_{\mathrm{d}}$ is number of paired differences.

Statistics for paired differences of prices and returns between CRSP and alternative data sources for Dow Jones Industrial securities, measured in levels and standardized against CRSP, are reported in Table 5. Comparison based on both levels and rates of paired price differences reveals that resemblance between unadjusted prices from Yahoo and CRSP is far better ( $\$ 0.00$ and $0.00 \%$ average paired difference) than relationships between CRSP and any other source based on adjusted prices. MSN Money had the most accurate adjusted prices relative to CRSP ( $\$ 0.02$ average difference in levels and $0.03 \%$ average rate of difference), followed by TeleChart ( $\$ 0.09$ and $0.29 \%$ on average), while Yahoo versus CRSP coverage was substantially inferior ( $\$ 3.01$ and $7.19 \%)$ to other data sources. With such huge values of t-statistics null hypotheses were rejected for both unadjusted and adjusted prices for all comparison between CRSP and alternative data sources, regardless of whether price differences were measured in levels or if they were standardized.

Table 5: Paired Price and Return Differences between Other Data Sources and CRSP for 30 Dow Jones Industrial Index Securities (1/1/2003 - 12/31/2007)

\begin{tabular}{|l|c|c|c|}
\hline \multirow{2}{*}{ Data } & \multirow{2}{*}{ Stat } & \multicolumn{2}{|c|}{ Less Adjusted CRSP } \\
\cline { 2 - 3 } & & Price & Returns \\
\cline { 2 - 4 } & Count & 37,740 & 37,710 \\
\hline TeleChart Adjusted Closing & Avg & $\$ 0.09$ & $0.01 \%$ \\
Prices/Returns & t test & $44.33 * * *$ & $22.02 * * *$ \\
\hline MSN Money Adjusted Closing & Avg & $\$ 0.02$ & $0.00 \%$ \\
Prices/Returns & t test & $15.50 * * *$ & $69.95 * * *$ \\
\hline Yahoo Closing Prices less & Avg & $\$ 0.00$ & $6.19 \%$ \\
CRSP Closing Prices & t test & $4.64 * * *$ & $102.2 * * *$ \\
\hline Yahoo Adjusted Closing & Avg & $\$ 3.01$ & $0.02 \%$ \\
Prices/Returns & t test & $299.61 * * *$ & $41.08^{* * *}$ \\
\cline { 2 - 4 }
\end{tabular}

$*, * *, * * *$ indicate statistical significance at $10 \%, 5 \%$ and $1 \%$ level.

The resemblance rank based on paired differences of returns from adjusted prices remained the same. While Yahoo is still the least accurate, returns are much closer to CRSP than was the case with prices. Although average level of return differences is measured in basis points, average standardized return difference based on adjusted prices is measured in percentage points. Even though magnitudes of price and return differences between 
CRSP and other data sources are small, the null hypothesis, that the mean difference between data sources is zero, is rejected due to large t-test values. This can be attributed to outliers and extremely large sample size, since t-test is designed for relatively small samples.

Paired price and return differences between CRSP and alternative data sources for small S\&P 500 securities, measured in levels and standardized against CRSP were also analyzed. The results are reported in Table 6.

Statistics in bold fonts again denote relevant comparison given the type of prices provided in the specific data set. As was the case with Dow Jones Industrial securities, resemblance of unadjusted prices from Yahoo and CRSP, both for levels and standardized price differences, is still far better (average paired differences remain at $\$ 0.00$ and $0.00 \%$ ) than when adjusted prices from any data source are used. While MSN Money continues to provide the most accurate relationship with CRSP ( $\$ 0.53$ and 27.33\%) when adjusted prices were used, Yahoo adjusted prices resembles CRSP ( $\$ 0.80$ and $34.57 \%$ ) better than TeleChart $(\$ 2.10$ and $75.10 \%)$. Accuracy rank is completely turned around when differences in returns are analyzed. TeleChart data match CRSP with the highest precision (\$0.01 and 0.75\%), followed by Yahoo (\$0.02 and 1.16\%) and MSN Money (\$0.06 and 1.76\%) had the lowest accuracy. Similar to Dow Jones Industrial securities, magnitude of standardized differences for returns is much smaller than for prices. Given that magnitudes of price and return differences for small S\&P 500 securities exceed those for Dow Jones Industrial Index securities, null hypothesis, that mean price and return differences between different sources of data are zero, is again rejected.

Table 6: Paired Price Differences between Other Data Sources and CRSP for 30 Randomly Selected Firms from Smallest $20 \%$ of S\&P 500 Securities $(1 / 1 / 2003-12 / 31 / 2007)$

\begin{tabular}{|l|c|c|c|}
\hline \multirow{2}{*}{ Data } & \multirow{2}{*}{ Stat } & \multicolumn{2}{|c|}{ Less Adjusted CRSP } \\
\cline { 2 - 4 } & & Prices & Returns \\
\hline \multirow{3}{*}{ TeleChart Adjusted Closing Prices/Returns } & Count & 31,935 & 29,714 \\
\cline { 2 - 4 } & Avg & $\$ 2.10$ & $0.01 \%$ \\
\cline { 2 - 4 } & t test & $57.26^{* * *}$ & $16.18^{* * *}$ \\
\hline \multirow{3}{*}{\begin{tabular}{c} 
MSN Money Adjusted Closing Prices/Returns \\
\cline { 2 - 4 }
\end{tabular}} & Avg & 31,965 & 29,771 \\
\cline { 2 - 4 } & t test & 30.53 & $21.75^{* * *}$ \\
\hline \multirow{2}{*}{$\begin{array}{l}\text { Yahoo Closing Prices less } \\
\text { CRSP Closing Prices/Returns }\end{array}$} & Count & 31,865 & 29,664 \\
\cline { 2 - 4 } & Avg & $\$ 0.00$ & 0.00 \\
\cline { 2 - 4 } $\begin{array}{l}\text { Yahoo Adjusted Closing } \\
\text { Prices/Returns }\end{array}$ & t test & 31,865 & 0.00 \\
\cline { 2 - 4 } & Count & $\$ 0.80$ & 29,664 \\
\cline { 2 - 4 } & Avg & $42.15 * * *$ & $0.02 \%$ \\
\hline
\end{tabular}

$*, * *, * * *$ indicate statistical significance at $10 \%, 5 \%$ and $1 \%$ level.

High maximum returns and lower mean standardized return difference for unadjusted than adjusted price from TeleChart, MSN Money and Yahoo survived the scrutiny of multiple checks but still elude acceptable explanation.

Overall, our results indicate that closing prices from free data sources, Yahoo and MSN Money in particular, resemble CRSP at least as well as, if not better than those from TeleChart, which is a fee charging commercial source of data. Hence, these free data sources seem to represent acceptable transitory CRSP substitutes for research purposes, especially for larger, well known firms, and more than an adequate tool for many teaching needs.

It seems that in addition to more-detailed charts and other tools for technical analysis, the biggest advantage provided by TeleChart is convenience in collecting data. Contrary to tedious and time consuming process of manually downloading data for each firm individually from Yahoo and MSN Money, a download utility in 
TeleChart does automatic bulk download for a whole list of ticker symbols. Fortunately, manual downloading can be automated using Excel add-in for MSN Money data or free shareware programs for Yahoo data.

\section{CONCLUSIONS}

Although CRSP has been accepted as the norm for research quality stock market data for more than 40 years, not all institutions of higher education can afford its subscription price. As a result of improvements in computing technology and increased interest in stock market transactions by individual investors, other data sources have become available. Concurrence between data from CRSP and other data sources was analyzed using closing prices and returns for 30 Dow Jones Industrial firms and 30 companies randomly selected from the smallest quintile of S\&P 500 firms for five years period, from 1/1/2003 through 12/31/2007from Yahoo, MSN Money and Worden Brothers TeleChart.

Mean-variance characteristics of prices and returns for CRSP and three alternative sources of data were analyzed first. For Dow Jones Industrial subsample of Blue Chip firms, null hypothesis that means of closing price are the same for CRSP and other data sources was rejected only for adjusted closing prices from Yahoo. For small S\&P 500 firms null hypothesis was not rejected only for unadjusted closing prices from Yahoo. When analysis was repeated for returns null was rejected for none of sources of data for Dow Jones firms. In the subsample of small S\&P 500 firms null was rejected only for returns from TeleChart.

The paired price and return differences between CRSP and other data sources were looked at next. Although price and return paired differences were generally measured in cents and basis points, null hypothesis was rejected for both prices and returns from all data sources for both Dow Jones and small S\&P 500 firms, due to large outliers. Another problem is extremely large number of observations, since t-test (average paired diff divided by the square root of summed variances divided by \# of observations) is designed for fewer observations. Data from MSN Money resembled CRSP the closest in all instances other than returns for small S\&P 500 firms when TeleChart was the most concurrent with CRSP.

The main result is that data from free sources, especially MSN Money, resemble CRSP as well as, if not better than, data from commercial TeleChart. This finding indicates that free data sources are acceptable transitory substitutes for CRSP for research purposes, and more than adequate for teaching needs. The advantage of convenient data downloading for TeleChart can be eliminated with an Excel add-in for MSN Money and shareware software for Yahoo data.

\section{AUTHOR INFORMATION}

Professor Racic's areas of expertise include corporate and international finance. He has also published work in outcome based assessment in finance education. While a Ph.D. student at the University of Pittsburgh's Katz School of Business, he received several teaching rewards and recognitions, including the Distinguish Professor Award from the 1999 Executive MBA class.

Denis P. Rudd, Ed.D, CHA, FMP, is an Full Professor and the director of the Hospitality and Tourism Program at Robert Morris University. Dr. Russ has more than 35 publications covering the spectrum of Hospitality and Tourism areas. Dr. Rudd is a fifth generation hotelier who began his career at his family's hotel in Windahm, New York at the Osborn House a two-hundred-and fifty room resort. He has also worked for the Breakers and the Biltmore Hotels in Palm Beach, Fla.

Dr. Frank Flanegin received his MBA from the Crummer School of Business at Rollins College and his Ph.D. from the University of Central Florida. Dr. Flanegin is a Professor of Finance and Head of the Accounting and Finance Department at Robert Morris University in Pittsburgh PA. Dr. Flanegin has more than 25 research publications in prestigious, and in addition to Dr. Flanegin's academic experience he has more than 30 years of hospitality industry experience with more than a decade of ownership and entrepreneurial experience. 


\section{REFERENCES}

1. Lankford, Kimberly and Sean O'Neill (1999). "Stock Search.” Kiplinger's Personal Finance Magazine, Vol. 53, Issue 11.

2. Maher, Matt, Diane Schooley and Phil Fry (2001). "Classroom Financial Analysis With Electronic bases." Journal of Education for Business, Vol. 76, Issue 3, p144, 5p.

3. McCracken, Harry, Lincoln Spector and Matt Lake (1998). "Best Free Financial Information.” PC World, Vol. 16 Issue 4, p114, 2p.

4. Sachdeva, Darshan (2007). "Students' Attitudes Towards Use Of Compustat In Teaching An Introductory Course In Business Finance.” Psychological Reports, Vol. 101 Issue 2, p353-356

\section{APPENDIX}

List of 30 Small S\&P 500 Companies used in the study

\begin{tabular}{|c|c|c|c|}
\hline Company Name & Ticker & Company Name & Ticker \\
\hline Authentidate Holding Corp & ADAT & Coffee Holding Co Inc & JVA \\
\hline Axesstel Inc & AFT & Logic Devices Inc & LOGC \\
\hline Air T Inc & AIRT & Medialink Worldwide Inc & MDLK \\
\hline Phazar Corp & ANTP & Mechanical Technology Incorporated & MKTY \\
\hline Flanigan's Enterprse Inc & BDL & Misonix Inc & MSON \\
\hline Chad Therapeutics A & CHAD & Nature Vision Inc & NRVN \\
\hline Consulier Engineering & CSLR & Northern Technology & NTIC \\
\hline Diomed Holdings Inc & DIO & Ohio Legacy Corp & OLCB \\
\hline Diodes Inc & DIOD & Ore Pharmaceuticals Inc Common & ORXE \\
\hline Envoy Capital Group Inc & ECGI & Overland Storage Inc & OVRL \\
\hline Forbes Medi-Tech Inc & FMTI & Pixelplus Co Ltd & PXPL \\
\hline First West Va Bancorp & FWV & Speedus Corp & SPDE \\
\hline Giga-Tronics Inc & GIGA & Star Buffet Inc & STRZ \\
\hline Hirsch International Corp Class A & HRSH & Valpey Fisher Corp & VPF \\
\hline Immucell Corp & ICCC & Zareba Systems Inc & ZRBA \\
\hline
\end{tabular}

